\title{
Qual a característica da campanha online de mulheres candidatas? Uma análise a partir das eleições brasileiras de 2018
}

\author{
What are the characteristics of online campaigns of female \\ candidates? An analysis based on the 2018 Brazilian elections
}

\author{
Camilla Quesada Tavares \\ Nayara Nascimento de Sousa
}

\section{Resumo}

Tem-se como objetivo investigar quais as características das campanhas no Facebook feitas por mulheres candidatas às eleiçóes de 2018. Considerando que as mulheres recebem poucos incentivos dos partidos para disputarem cargos públicos, redes sociais digitais representam uma possibilidade de equilibrar a campanha entre os atores, já que nos espaços tradicionais, como rádio e TV, elas tendem a obter menos tempo do que candidatos homens. Busca-se compreender quais as estratégias de campanha utilizadas por elas nas fanpages do Facebook, tendo como foco as questóes de gênero. Para atingir esses objetivos, são analisadas as campanhas de seis candidatas com diferentes trajetórias na política. O corpus é composto por 1.958 postagens realizadas durante o primeiro turno da campanha eleitoral nas fanpages do Facebook, e a metodologia é de análise de conteúdo quantitativa. Resultados indicam que as candidatas pouco apresentam um discurso que aborde gênero, e quando o fazem é de forma a reforçar estereótipos.

\section{Palavras-chave}

Mulheres; Campanha Eleitoral; Facebook.

\section{Abstract}

The aim of this paper is to investigate the characteristics of the campaign by women candidates for the 2018 elections on Facebook. Considering that women receive little incentive from parties to run for public office, digital social networks represent a way of balancing the campaign among actors, as in traditional spaces, such as radio and television, they tend to get less time than male candidates. Thus, we seek to understand which campaign strategies they use in Facebook fan pages, with particular focus on gender issues. To achieve the objectives, we analyzed the campaign of six candidates who have different trajectories in politics. The research corpus consists of 1,958 posts made during the first round of the election campaign on Facebook fan pages, based on the quantitative content analysis methodology. The results indicate that the candidates have little gender discourse, and, when they do have it, it reinforces stereotypes.

\section{Keywords}

Women; Electoral Campaign; Facebook. 


\section{Introdução ${ }^{1}$}

Ao longo do século $\mathrm{XX}$, as mulheres brasileiras conquistaram diversos direitos políticos e civis, entre eles o reconhecimento da equidade de gênero pela Constituição de 1988. Apesar disso, a mulher enfrenta uma série de dificuldades na vida social e política que são promovidas justamente pela diferença entre o ser homem e o ser mulher. Um desses enfrentamentos acontece na arena política. Uma série de autores e autoras já trataram da dificuldade de as mulheres adentrarem o campo político como candidatas a cargos públicos ou indicadas devido às suas competências profissionais (ARAÚJO, 2005; FINAMORE e CARVALHO, 2006; MIGUEL e BIROLI, 2010 e 2014). Os principais entraves são a dupla jornada de trabalho e a falta de incentivo dos partidos, principalmente por meio dos recursos financeiros (CAMPOS, 2019) e pelo acesso às mídias tradicionais para fazer campanha (CERVI, 2011).

Apesar de ser a maioria da população brasileira ${ }^{2}$ e de ter observado avanços formais - como a cota de gênero - a atuação da mulher na vida pública ainda é muito baixa. Em termos comparativos, na Arábia Saudita, onde as mulheres conquistaram o direito de dirigir autonomamente somente em 2018, há mais representantes femininas nas instâncias de poder político do que o Brasil, onde, atualmente, $85 \%$ do legislativo é composto por homens (CAMPOS, 2019). Além disso, há poucos incentivos partidários para que as mulheres façam uma campanha competitiva, e elas dependem da distribuição dos recursos partidários para conseguirem acessar os espaços tradicionais de campanha, como a propaganda televisiva.

Se até poucos anos atrás a centralidade da campanha estava no Horário Gratuito de Propaganda Eleitoral (HGPE) televisivo, com a minirreforma eleitoral e os avanços das plataformas online, hoje ela acontece fortemente nas redes sociais (ALBUQUERQUE e TAVARES, 2018). A particularidade da campanha online é que ela pode ser feita independentemente do partido; cada candidato e candidata pode criar uma página, seja em sites ou redes sociais, e utilizar aquele espaço como um lugar da comunicação política. Deste modo, as candidatas encontram ali um ambiente mais livre (no sentido da organização da campanha) e direto para se dirigir

\footnotetext{
1 Os dados apresentados neste trabalho são um recorte dos resultados da pesquisa de iniciação científica da segunda autora, desenvolvida na Universidade Federal do Maranhão (UFMA). A pesquisa recebeu financiamento do CNPq de agosto de 2018 a julho de 2019.

${ }^{2}$ As mulheres somam 51,6\% da população do Brasil, de acordo com dados do Instituto Brasileiro de Geografia e Estatísticas (IBGE) de 2017, e consequentemente a maior parte do eleitorado, com 52,5\% - segundo o Cadastro Eleitoral (MULHERES..., 2018).
} 
aos eleitores, fazendo, especialmente das redes sociais, o lugar de excelência da campanha.

A partir desta discussão, o trabalho tem como objetivo investigar como os discursos de mulheres candidatas são construídos nesses espaços para se compreender o tipo de campanha que é feito, a quem se dirige e se tal campanha se difere, de alguma maneira, das campanhas normativas, feitas por homens. De modo complementar, busca-se verificar quais as estratégias discursivas utilizadas por essas mulheres no Facebook, identificando os temas discutidos e se as questôes de gênero estáo presentes. $\mathrm{O}$ conteúdo analisado é proveniente das fanpages das seguintes candidatas: Ângela Portela (PDT-RR), Jandira Feghali (PCdoB-RJ), Lúcia Vânia (PSB-GO), Eliziane Gama (PPS-MA), Roseana Sarney (MDB-MA) e Fátima Bezerra (PT-RN). O corpus é composto por 1.958 postagens, publicadas durante o primeiro turno das eleições de 2018. A metodologia utilizada é a análise de conteúdo quantitativa (KRIPPENDORFF, 1989).

O estudo se justifica pela baixa presença de trabalhos que considerem mulheres e campanhas na perspectiva da construção do discurso na comunicação política (PANKE e IASULAITIS, 2016). Ainda que haja pesquisas sobre financiamento, dirigentes partidárias e modos de fazer campanha no horário eleitoral (MARTINS e ALTMANN, 2018; MENDONÇA e OGANDO, 2013), entre outras questóes, aquelas que se preocupam com os modos de construção das campanhas e seus elementos de gênero no ambiente online ainda são incipientes. Portanto, ao estudar a construção dos discursos das mulheres nas redes sociais, têm-se resultados que olham especialmente para as campanhas e os discursos que marcam essas disputas em particular.

O texto está dividido em quatro partes além desta introdução. A seguir são apresentadas as discussões teóricas que embasam o trabalho, tendo como foco as campanhas femininas e as campanhas nas redes sociais. Na sequência, são abordados os procedimentos metodológicos, seção em que também se faz uma breve contextualização das mulheres candidatas que integram este estudo. A quarta parte é dedicada à discussão e análise dos dados e, por fim, são apontadas as principais conclusões. 


\section{Desafios da campanha eleitoral feminina e as possibilidades oferecidas pelas redes sociais online}

Apesar do visível avanço das mulheres na política, esse espaço ainda é dominado por homens (BEARD, 2018; PANKE e IASULAITIS, 2016; HOLTZBACHA, 2013; MIGUEL e BIROLI, 2010). Segundo o Tribunal Superior Eleitoral, nas eleições 2018 tivemos um aumento de $52,4 \%$ de candidatas eleitas em relação a 2014, ainda que a desproporção entre homens e mulheres continue alarmante (NÚMERO..., 2019). Diversos autores apontam que as mulheres enfrentam muitos desafios para adentrar no mundo da política (SACCHET e SPECK, 2012; ARAÚJO, 2005), os quais vão desde a candidatura (obter recursos e tempo para a campanha) até o enfrentamento dos estereótipos sociais (a desconfiança quanto à capacidade de gestão e competência, as pressões e julgamentos diante da maternidade e casamento etc.) (PANKE e IASULAITIS, 2016; HOLTZ-BACHA, 2013; MIGUEL e BIROLI, 2010).

Miguel e Biroli (2010) explicam que as mulheres precisam ultrapassar barreiras quando almejam atuar na política, começando pelo enfrentamento da divisão sexual do trabalho - os afazeres domésticos, por exemplo, durante muito tempo foram obrigações femininas, e, mesmo com as transformações da sociedade, as mulheres ainda convivem sob o espectro de um modelo patriarcal e machista (BEARD, 2018). Nesse sentido, as mulheres acabam se sobrecarregando e cumprindo uma dupla jornada de trabalho - dentro e fora do lar -, o que pode se constituir num problema para quem se candidata aos cargos políticos sem contar com alguém que partilhe as atividades domésticas.

Outro problema são os julgamentos que a sociedade faz das mulheres: mesmo quando conseguem sucesso na carreira política, elas podem passar por situações sexistas, como, por exemplo, questionamentos em relação à maternidade, o que normalmente não acontece com homens (PANKE e IASULAITIS, 2016; MIGUEL e BIROLI, 2010). Holtz-Bacha (2013) acrescenta que a sociedade impóe expectativas que nunca são satisfatórias em relaçáo ao comportamento e personalidade das mulheres: se elas são frias, calculistas e agressivas, assim como se espera que os homens sejam, podem ser rejeitadas porque estão muito "masculinizadas"; mas se elas se mostram muito femininas, podem ser vistas como inaptas para a política (BEARD, 2018; HOLTZ-BACHA, 2013). Uma vez que ingressem na vida política, parte da sociedade espera que as mulheres sejam mais conciliadoras e se voltem para áreas ligadas ao cuidado e assistencialismo, como a saúde, infância, educaçáo, pobreza, 
bem-estar social, meio ambiente (PANKE e IASULAITIS, 2016). Ao contrário, a expectativa para os homens é o protagonismo na economia, política externa, segurança etc. (HOLTZ-BACHA, 2013; MIGUEL e BIROLI, 2010).

Ainda sobre as barreiras para as candidaturas, Miguel e Biroli (2010) apontam que muitas mulheres dependem dos recursos dos partidos para custear a campanha, especialmente aquelas que não dispõem do capital da família. Cervi (2011) também explica que o tempo no HGPE pode ser importante na campanha, especialmente na televisão, por ser o meio de comunicação mais utilizado pelos brasileiros. Assim, o alcance desse aparelho permite aos eleitores conhecer quem disputa os cargos políticos, e geralmente os partidos priorizam os candidatos homens, em detrimento das mulheres, que saem em desvantagem. Apesar de dependerem mais dos recursos partidários, elas são as que menos recebem (SACCHET e SPECK, 2012; MASSAMBANI e CERVI, 2011).

Para tentar minimizar essa diferença, o Supremo Tribunal Federal decidiu, em março de 2018, que os partidos devem destinar recursos para as candidatas na mesma proporção das candidaturas (CAMPOS, 2019). Na prática, isso significa que elas devem receber pelo menos $30 \%$ de todos os recursos públicos de campanha, além de ter acesso à no mínimo 30\% do tempo total de rádio e TV. No entanto, a pouca divulgação e a burocracia para solicitar esses recursos são alguns dos fatores que dificultam sua implementação efetiva (CAMPOS, 2019). Por outro lado, a internet traz possibilidades para as campanhas, com a maior interação entre candidatos/as e eleitores/as e a potencialização do conteúdo divulgado nas redes sociais (MASSUCHIN e TAVARES, 2015; CERVI, 2011; AGGIO e REIS, 2013; PANKE e THAUNY, 2013).

O Facebook, enquanto rede social com maior número de usuários no Brasil, se tornou um importante instrumento de campanha (MASSUCHIN e TAVARES, 2015; PANKE e THAUNY, 2013; PENTEADO, 2012). Silva, Rossetto e Carreiro (2014) argumentam que essa rede social pode ser usada para potencializar os valores democráticos, pois amplia o alcance das discussões realizadas pelos cidadãos. Penteado (2012, p. 50) acrescenta que "[...] as redes também podem funcionar como espaço para a circulação e produção de informações políticas ampliando o público e as possibilidades de participação política". O Facebook já foi objeto de diversos trabalhos da área da comunicação política (MASSUCHIN e TAVARES, 2015; AGGIO e REIS, 2013; PANKE e THAUNY, 2013), mas não em se tratando de candidaturas femininas. Massuchin e Tavares (2015), por exemplo, apontam que a campanha nessa rede social adota estratégias de comunicação para conquistar os 
eleitores e mobilizá-los, com destaque para a tematização como estratégia e divulgação da agenda das/os candidatas/os. Panke e Thauny (2013) explicam que os conteúdos veiculados no Facebook podem gerar visibilidade, apoio e propagação às/aos candidatas/os, muito em razão das ferramentas próprias da plataforma, como o curtir (reagir), compartilhar e comentar. Aggio e Reis (2013) indicam que o Facebook possibilita a integração da imagem, vídeo e áudio, enriquecendo as mensagens difundidas pelas/os candidatas/os. Assim, essa rede se torna uma grande aliada das candidaturas femininas, por meio da qual é possível divulgar conteúdos em diversos formatos e dialogar diretamente com os eleitores em potencial.

$\mathrm{O}$ aumento das mulheres disputando as eleiçóes e, consequentemente, sendo eleitas, no entanto, não significa necessariamente uma ruptura com o padrão de desigualdade de gênero (MIGUEL e BIROLI, 2010; REZENDE, 2017). Ou seja, é necessário ir além de eleger mulheres, sendo imprescindível que elas tenham propostas que dialoguem com os problemas sociais e de gênero, de forma a avançar nas pautas e superar o machismo e o sexismo. Em relação às candidaturas, para Panke e Iasulaitis (2016), os estereótipos de gênero por vezes são usados como estratégia de campanha e podem tanto reforçar os atributos considerados femininos para sensibilizar os eleitores - conciliação, diálogo -, quanto as características ditas masculinas, para se aproximar daquilo que seria o "ideal" na política - o pulso firme e a liderança, por exemplo. Esses são alguns dos pontos que se busca investigar neste trabalho, mas por meio da campanha online feita por elas, algo ainda pouco explorado na literatura - que, quando trata de candidaturas femininas, ainda fica restrita à análise do HGPE.

No tópico a seguir, apresentam-se os aspectos metodológicos da pesquisa, bem como um breve histórico das candidatas selecionadas neste trabalho. Após esta parte, passa-se para a discussão dos resultados.

\section{Apresentação dos procedimentos metodológicos}

Para atingir os objetivos da pesquisa, primeiramente foram selecionadas seis candidatas que concorreram às eleiçôes de 2018, levando em conta as regiōes do país ${ }^{3}$, a representatividade política e a diversidade dos cargos concorridos, além da verificação se as respectivas fanpages do Facebook eram atualizadas. Considerando

\footnotetext{
${ }^{3}$ A pesquisa contempla outras mulheres candidatas, integrantes da região Sul, bem como de outros estados além dos já incluídos neste trabalho. No entanto, trata-se de uma pesquisa ainda em andamento. O banco de dados completo será utilizado em trabalhos futuros.
} 
esses critérios, chegou-se às seguintes mulheres para compor este trabalho: Ângela Portela ${ }^{4}$ (PDT-RR), Jandira Feghali5 (PCdoB-RJ), Lúcia Vânia ${ }^{6}$ (PSB-GO), Eliziane Gama $^{7}$ (PPS-MA), Roseana Sarney ${ }^{8}$ (MDB-MA) e Fátima Bezerra9 (PT-RN). Optouse por três candidatas no Nordeste pela oportunidade de comparar campanhas do Maranhão, estado de origem da pesquisa, com Roseana e Eliziane Gama, e pela relevância da candidatura da única mulher eleita para o governo de um estado em 2018, que foi Fátima Bezerra, no Rio Grande do Norte. O Facebook foi escolhido por se tratar da rede social mais utilizada pelos brasileiros, e, nesse sentido, possuir maior abrangência ${ }^{10}$.

A pesquisa utilizou o método da análise de conteúdo, de viés quantitativo, por permitir que os dados sejam categorizados e comparados, para se chegar às conclusóes, com base num referencial (BAUER, 2002). Assim, foi elaborado um livro de códigos que abarcasse tanto as estratégias de campanha quanto questôes relacionadas ao gênero, com base nos estudos de Panke (2016). Ao longo do primeiro turno da campanha eleitoral de 2018 - 16 de agosto a 6 de outubro -, utilizou-se o aplicativo Netvizz para coletar todas as postagens realizadas nas fanpages das candidatas, chegando ao total de 1.958 postagens que integram este estudo. O grupo de Pesquisa em Comunicação, Política e Sociedade (COPS) foi responsável pela codificação dos dados, sendo que os cinco codificadores responsáveis passaram por treinamento para evitar inconsistências na coleta.

As variáveis consideradas na análise da pesquisa são: publicações nas fanpages das candidatas pelo critério da disputa ou não à reeleição; quantidade de postagens de cada candidata e observando o cargo em disputa; o tipo de abordagem do discurso nos posts entre feminino, feminista e sem referência ao gênero ${ }^{11}$; o direcionamento do

\footnotetext{
${ }^{4}$ Disponível em: <https:/www.facebook.com/angelaportelaRR/>. Acesso em: 4 set. 2019

${ }^{5}$ Disponível em: <https://www.facebook.com/sigajandira2/>. Acesso em: 4 set. 2019

${ }^{6}$ Disponível em: <https://www.facebook.com/luciavaniasenadora/>. Acesso em: 4 set. 2019

${ }^{7}$ Disponível em: <https://www.facebook.com/elizianegama/>. Acesso em: 4 set. 2019

${ }^{8}$ A fanpage do Facebook da então candidata não está mais disponível.

${ }^{9}$ Disponível em: <https://www.facebook.com/FatimaBezerra13/>. Acesso em: 4 set. 2019

${ }^{10}$ Segundo o próprio Facebook, em 2018 o Brasil atingiu a marca de 127 milhóes de usuários ativos mensais, sendo um dos cinco maiores mercados mundiais da companhia (OLIVEIRA, 2018).

${ }^{11}$ A abordagem do discurso refere-se ao modo como a candidata dirige-se ao seu eleitorado - se por um discurso mais voltado às questôes femininas, feministas ou sem uma abordagem clara. No caso de discursos femininos, são aqueles em que a candidata busca uma identificação por aspectos do imaginário feminino, como por exemplo, ser mãe, gostar de cuidar das pessoas, ser responsável pelo cotidiano da casa, dentre outros. No caso da abordagem feminista, o discurso é mais voltado à
} 
discurso para mulheres, outras minorias (idosos, deficientes, indígenas, negros etc.) ou sem referência ao gênero; o discurso com referência ou não ao movimento feminista; a presença ou ausência de crítica à baixa participação feminina na política; os estereótipos de gênero presentes nas postagens com base em Panke (2016), sendo eles a dona de casa, guerreira, mãe, atenciosa/sensível, submissa, trabalhadora ou não identificado; o apoio ou não do patrono; e os temas das publicaçôes. Sobre os estereótipos de gênero, Panke (2016) explica que eles são imagens mentais formadas com base em determinados aspectos e que produzem expectativas sobre um grupo ou categoria. A partir de estudos com campanhas femininas presidenciais na América Latina, a autora distingue seis tipologias de estereótipos: dona de casa (a campanha reforça as candidatas nas atividades domésticas), guerreira (associadas à liderança e luta feminina), mãe (desempenha seu papel na maternidade), atenciosa/sensível (cuida das pessoas e exerce funçôes ligadas a isso, como professoras, médicas etc.), submissa (mulheres subordinadas aos homens, ainda sejam líderes, elas demonstram que precisam da figura masculina em algum momento), e a trabalhadora (que trabalha fora do lar, podendo ou não ser mãe).

Tratando brevemente da trajetória das candidatas na política, a professora Ângela Portela foi primeira-dama de Roraima em 2002, quando seu marido, Flamarion Portela, se elegeu como Governador (2002-2004). Foi Deputada Federal pelo PTC (2007-2011) e concorreu ao Governo de Roraima pelo PT em 2014, mas foi derrotada. Eleita Senadora pelo PT em 2010 (2011-2019), disputou a reeleição pelo PDT em 2018, mas não venceu.

Eliziane Gama é jornalista por formação, filiou-se ao PPS e se candidatou pela primeira vez a um cargo político no Maranhão em 2006, quando foi eleita Deputada Estadual (2007-2011) e reeleita em 2010 (2011-2015). Disputou a Prefeitura de São Luís por duas vezes, em 2012 e 2016, mas foi derrotada em ambas as eleiçóes. Em 2014, foi a única mulher eleita Deputada Federal no Maranhão (2015-2019), e em 2018 conquistou uma vaga no Senado.

A médica Jandira Feghali também possui uma carreira atuante na política do Rio de Janeiro, sempre disputando cargos pelo PCdoB. Foi eleita Deputada Estadual em 1986 (1987-1991) e, desde então, vem se reelegendo como Deputada Federal (1991-1995, 1995-1999, 1999-2003, 2003-2007, 2011-2015, 2015-2019), inclusive

discussão sobre direitos das mulheres, necessidade de ocupar os espaços políticos, críticas à sociedade machista e patriarcal, dentre outros. No entanto, se o discurso não abordava nenhuma dessas questóes, considerava-se um discurso neutro, e o post era classificado como "sem referência ao gênero". 
nas eleições de 2018, totalizando sete mandatos nesse mesmo cargo. Concorreu sem sucesso à Prefeitura do Rio de Janeiro em 2008 e 2016, e ao Senado em 2006.

Lúcia Vânia advém de uma família de políticos, incluindo senadores e deputados. Foi primeira-dama de Goiás, durante o mandato de seu ex-marido, Irapuan Costa Júnior, como Governador (1975-1979). Jornalista por formação, Lúcia Vânia filiou-se ao PSDB e foi eleita Deputada Federal por esse mesmo estado por três vezes (1987-1991, 1991-1995 e 1999-2003), e Senadora por duas vezes (2003-2019). Foi derrotada nas eleições de 1994, quando se candidatou à Governadora pelo PP; em 2000, concorreu à Prefeitura de Goiânia pelo PSDB; e, em 2018, disputou a reeleição no Senado pelo PSB.

Roseana Sarney faz parte de uma família de políticos bastante influente no Maranhão. Seu pai, José Sarney, já ocupou os cargos da Presidência da República, Senador pelo Amapá, Deputado Federal, Senador e Governador do Maranhão. Os irmãos de Roseana, Sarney Filho e Fernando Sarney, também seguem a carreira política. Roseana Sarney é formada em Sociologia e ingressou na política quando eleita à Deputada Federal pelo PFL (1991-1994). Foi Governadora por quatro mandatos (1995-1999, 1999-2002, 2009-2011, 2011-2014) e Senadora (20032009). Em 2018, concorreu ao Governo pelo MDB, mas não conseguiu se eleger.

Fátima Bezerra é a única mulher eleita governadora no país em 2018, pelo Rio Grande do Norte. Graduada em Pedagogia, Fátima Bezerra passou por vários cargos na área da Educação antes de ingressar na carreira política, com filiação ao PT. Foi Deputada Estadual por dois mandatos (1995-1999 e 1999-2003), Deputada Federal por três vezes (2003-2007, 2007-2011 e 2011-2016) e Senadora (20152019). Candidatou-se à Prefeitura de Natal em quatro eleiçôes (1996, 2000, 2004 e 2008), sem sucesso. Em 2018, foi eleita a única mulher governadora de um estado brasileiro, pelo PT.

A partir do breve relato do percurso das candidatas na política, percebe-se que todas elas já possuem uma carreira nesse espaço, ocupando vários cargos ao longo dos anos, mas é importante ressaltar que algumas tiveram certa facilitação pela influência familiar, o que é bastante comum na política brasileira (MIGUEL e BIROLI, 2010), como é o caso da Roseana Sarney (MA), Ângela Portela (RR) e Lúcia Vânia (GO), mas isso não significa dizer que as demais não contaram com o apoio de políticos em suas candidaturas. Agora que se conhece as candidatas e os procedimentos metodológicos que orientaram a pesquisa, passemos à apresentaçáo dos resultados. 


\section{Como as candidatas utilizaram as fanpages para fazer campanha}

O primeiro resultado apresentado compara as publicaçóes nas fanpages das candidatas pelo critério da disputa ou não à reeleição ${ }^{12}$, para analisar se a possibilidade da renovação do mandato ou um novo poderia influenciar na manutenção das postagen $s^{13}$.

Tabela 1 - Publicaçôes das candidatas à reeleição

\begin{tabular}{c|c|c}
\hline & $\mathbf{N}$ & $\mathbf{\%}$ \\
\hline Sim & 985 & $50,3 \%$ \\
\hline Náo & 973 & $49,7 \%$ \\
\hline Total & 1.958 & $100,0 \%$ \\
\hline
\end{tabular}

Fonte: COPS (2019)

Os dados mostram que $50,3 \%$ das postagens correspondem às fanpages do Facebook das candidatas que estavam na disputa pela reeleição, e 49,7\% se referem às publicações das mulheres que não concorriam pela renovação do mandato. Os percentuais aproximados indicam que a manutenção das fanpages não é influenciada pelo tipo de disputa, ou seja, se a disputa é pelo novo mandato ou para continuar no cargo já ocupado por elas desde o pleito anterior, isso não parece ser um diferencial para se publicar mais ou menos nas fanpgaes. Dessa forma, entende-se que a utilização do Facebook enquanto espaço de divulgação de publicações para a campanha pode se suceder de forma semelhante entre essas mulheres, levando em conta que, em tese, aquelas que concorriam à reeleição teriam uma vantagem de um maior volume de conteúdo, por conta do que foi realizado no cargo que ocuparam, além das propostas para a renovação deste.

Em seguida, indicam-se as temáticas identificadas nas postagens das candidatas. O Gráfico 1, a seguir, mostra os temas predominantes nos posts publicados ao longo do primeiro turno da campanha eleitoral, de modo agregado. Conforme outros estudos apontam, o Facebook é utilizado majoritariamente para depositar informaçóes da campanha, mostrar as carreatas e divulgar pesquisas de

\footnotetext{
12 Ressaltamos que três candidatas concorriam ao novo mandato (Fátima Bezerra, Eliziane Gama e Roseana Sarney) e três disputavam a reeleição (Lúcia Vânia, Jandira Feghali e Ângela Portela).

${ }^{13}$ Manutenção das fanpages significa a atualização das postagens.
} 
intenção de voto; é o que diz respeito à metacampanha ${ }^{14}$ (30,4\%), principal tema identificado nas postagens. Percebe-se que, apesar de as redes sociais terem adquirido maior importância nas eleiçóes, as candidatas consideradas nesta pesquisa utilizaram as fanpages como repositório de conteúdo das próprias campanhas.

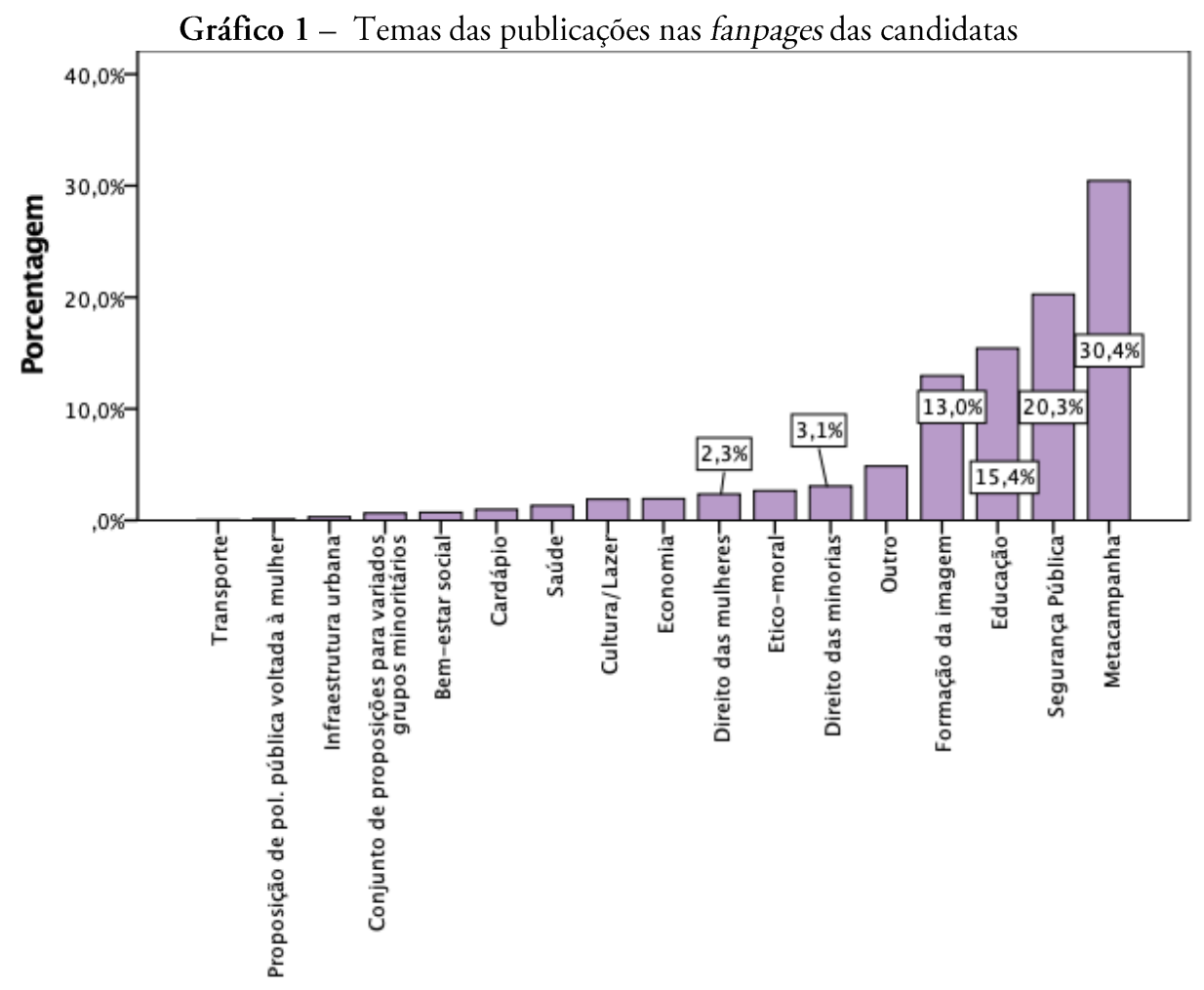

Fonte: COPS (2019).

Tema

Chama atenção que a segurança pública foi o segundo tema mais abordado pelas candidatas $(20,3 \%)$, revelando um dado diferente do que foi encontrado em estudos sobre campanhas femininas - Miguel e Biroli (2010) apontam que geralmente as mulheres optam por temas ligados ao assistencialismo. A explicação para isso é que o contexto da segurança em alguns estados contribuiu para que esse tema fosse mais debatido nas postagens das candidatas. É o caso do Rio Grande do Norte, que passou por uma crise no sistema penitenciário, agravada desde 2017

${ }^{14}$ Metacampanha diz respeito a assuntos da própria campanha (ALBUQUERQUE, 1999), como agenda do candidato e divulgação de resultados de pesquisas de intenção de voto. 
(BARBOSA e RAFAEL, 2018), e na segurança pública, em 2018, culminando com a greve dos policiais e bombeiros, o que gerou ondas de violência pelo estado (ALBUQUERQUE, 2018). A crise na segurança pública no Rio de Janeiro chegou à intervenção federal em 2018 (BARBON e VETTORAZZO, 2018).

Educação foi o terceiro tema mais citado pelas candidatas $(15,4 \%)$, em consonância com pesquisas da área (PANKE e IASULAITIS, 2016; HOLTZBACHA, 2013; MIGUEL e BIROLI, 2010). Interessante observar também que a formação da imagem não esteve entre as temáticas mais presentes nas fanpages, mas apresenta um relevante percentual de publicaçóes $(13,0 \%)$. Importante ainda ressaltar o baixo percentual de temas voltados para os direitos das mulheres $(2,3 \%)$ e de outras minorias $(3,1 \%)$. O que se percebe é que as candidatas pouco propuseram açóes especificamente para mulheres, o que pode ser preocupante quando Miguel e Biroli (2010) explicam que a inclusão feminina na política precisa abarcar os problemas sociais e de gênero para superá-los, e não meramente reproduzir as estruturas existentes. Ou seja, a representação feminina depende da atuação das mulheres enquanto forma de enfrentar as desigualdades, caso contrário, as mulheres permanecerão sub-representadas, mesmo com o maior número de eleitas.

A tabela a seguir mostra o número de posts que cada candidata fez na fanpage. A finalidade aqui é observar se foram encontrados resultados diferentes entre o tipo do cargo em disputa.

Tabela 2 - Publicaçôes de acordo com as candidatas

\begin{tabular}{c|c|c|c}
\hline Cargo & Candidata & $\mathbf{N}$ & $\mathbf{\%}$ \\
\hline \multirow{3}{*}{ Governadora } & Fátima Bezerra & 534 & $27,3 \%$ \\
\cline { 2 - 4 } Senadora & Roseana Sarney & 109 & $5,6 \%$ \\
\hline \multirow{3}{*}{ Deputada Federal } & Ângela Portela & 199 & $10,2 \%$ \\
\cline { 2 - 4 } & Eliziane Gama & 330 & $16,8 \%$ \\
\cline { 2 - 4 } & Lúcia Vânia & 232 & $11,8 \%$ \\
\hline \multicolumn{2}{c|}{ Total } & 554 & $28,3 \%$ \\
\hline
\end{tabular}

Fonte: COPS (2019).

Os dados indicam que o tipo de candidatura pode não ter relação com a manutenção das fanpages, pois as mulheres que mais publicaram no Facebook disputam para cargos diferentes: Jandira Feghali, concorrendo à Deputada Federal $(28,3 \%)$, Fátima Bezerra, disputando para Governadora (27,3\%) e Eliziane Gama, 
concorrendo ao Senado $(16,8 \%)^{15}$. Pensando no pouco tempo no $\mathrm{HGPE}^{16}$ e a possibilidade disso potencializar a campanha nas redes sociais, tal fator divergiu de candidata para candidata. Jandira Feghali, que dispunha de apenas 31s no horário eleitoral televisivo, foi a candidata que mais postou conteúdo no Facebook, ou seja, a estratégia pode ter sido aproveitar o alcance da fanpage para chegar nos eleitores e eleitoras. Por outro lado, Ângela Portela também tinha poucos segundos no horário eleitoral (48s) e seguiu na contramão, com poucos posts na fanpage (10,2\%).

Outras candidatas que tinham um tempo relativamente considerável no HGPE souberam tanto aproveitar os minutos na televisão e rádio quanto publicar bastante no Facebook. É o caso de Eliziane Gama, que tinha 3 min24s no horário eleitoral televisivo e 16,8\% dos posts, além de Fátima Bezerra, com 1 min30s no HGPE da televisão e 27,3\% das publicações na fanpage.

Considerando ainda a relação entre os estados com maior ou menor acesso à internet e a utilização das redes sociais pelas candidatas, também percebemos que é um critério que não se aplica. O Nordeste é a região brasileira com menos acesso à internet, segundo dados da TICs Domićlios 2018 (COMITÊ, 2019), com 57\% dos domicílios possuindo acesso à internet. Já o Maranhão possui um dos menores percentuais de acesso à internet do país, segundo a Pesquisa Brasileira de Mídia (BRASIL, 2016), e mesmo assim nota-se uma discrepância na manutenção das fanpages das candidatas Roseana Sarney e Eliziane Gama, ambas disputando cargos no estado. Roseana foi a que menos utilizou o Facebook (5,6\%), talvez seguindo esse raciocínio de que os maranhenses não possuem tanto acesso à internet, deixando as redes sociais de lado para priorizar outras estratégias de campanha, como o HGPE na televisão (2min32s), carreatas etc. Entretanto, Eliziane percorreu o caminho contrário, apostando, sim, nas redes sociais e publicando bastante no Facebook $(16,8 \%)$ - ou seja, o acesso dos eleitores e eleitoras à internet pode ou não influenciar na campanha online, e vai depender das estratégias de cada candidata.

\footnotetext{
$15 \mathrm{O}$ partido pode representar um fator de distinção, e não o cargo, já que partidos à esquerda do espectro ideológico tendem a incentivar a maior participação da mulher na política (ARAÚJO e ALVES, 2007), e oferecer maior tempo no HGPE para as mulheres candidatas, pelo menos a cargos proporcionais (TAVARES e MASSUCHIN, 2019). Isso pode refletir também na campanha feita nas redes sociais. No entanto, são necessários outros tipos de análises para testar esta hipótese, algo que vai além dos objetivos deste trabalho.

${ }^{16}$ O tempo no HGPE na televisão para cada candidata era: Eliziane Gama (Sen.) - 3min24s, Roseana Sarney (Gov.) - 2min32s, Fátima Bezerra (Gov.) - 1min30s, Lúcia Vânia (Sen.) - 1min20s, Ângela Portela (Sen.) - 48s, Jandira Feghali (Dep. Fed.) - 31s.
} 
$\mathrm{Na}$ sequência, tem-se o comparativo das publicações das fanpages com base na abordagem do discurso de cada candidata, entre feminino, feminista e sem referência ao gênero. De forma geral, em $85,5 \%$ das postagens na fanpage do Facebook das candidatas, não houve referência ao gênero, ou seja, em 1.674 posts, elas não se preocuparam em fazer qualquer menção às relações de gênero. Já 9,3\% das publicações possuíam abordagem feminina, ou seja, são posts que reforçavam o estereótipo feminino, como o papel tradicional da mulher na sociedade - mãe, esposa etc. Em apenas $5,2 \%$ das postagens, verifica-se um discurso feminista, o que representa um percentual muito baixo. Isso significa que essas mulheres optaram por uma campanha no Facebook com abordagem generalista, aproximando-se do que vemos nas campanhas masculinas, sem considerar suas próprias condições enquanto mulheres.

Tabela 3 - Publicações com base na abordagem do discurso por candidata

\begin{tabular}{|c|c|c|c|c|c|}
\hline & & Feminino & Feminista & $\begin{array}{c}\text { Sem } \\
\text { referência }\end{array}$ & Total \\
\hline \multirow[b]{2}{*}{ Ângela Portela } & $\mathrm{N}$ & 15 & 7 & 177 & 199 \\
\hline & $\%$ & $0,8 \%$ & $0,4 \%$ & $9,0 \%$ & $10,2 \%$ \\
\hline \multirow[b]{2}{*}{ Fátima Bezerra } & $\mathrm{N}$ & 31 & 74 & 429 & 534 \\
\hline & $\%$ & $1,6 \%$ & $3,8 \%$ & $21,9 \%$ & $27,3 \%$ \\
\hline \multirow[b]{2}{*}{ Roseana Sarney } & $\mathrm{N}$ & 2 & 1 & 106 & 109 \\
\hline & $\%$ & $0,1 \%$ & $0,1 \%$ & $5,4 \%$ & $5,6 \%$ \\
\hline \multirow[b]{2}{*}{ Eliziane Gama } & $\mathrm{N}$ & 4 & 1 & 325 & 330 \\
\hline & $\%$ & $0,2 \%$ & $0,1 \%$ & $16,6 \%$ & $16,9 \%$ \\
\hline \multirow[b]{2}{*}{ Lúcia Vânia } & $\mathrm{N}$ & 17 & 2 & 213 & 232 \\
\hline & $\%$ & $0,9 \%$ & $0,1 \%$ & $10,9 \%$ & $11,8 \%$ \\
\hline \multirow[b]{2}{*}{ Jandira Feghali } & $\mathrm{N}$ & 113 & 17 & 424 & 554 \\
\hline & $\%$ & $5,8 \%$ & $0,9 \%$ & $21,7 \%$ & $28,3 \%$ \\
\hline \multirow[b]{2}{*}{ Total } & $\mathrm{N}$ & 182 & 102 & 1.674 & 1.958 \\
\hline & $\%$ & $9,3 \%$ & $5,2 \%$ & $85,5 \%$ & $100,0 \%$ \\
\hline
\end{tabular}

Fonte: COPS (2019).

Olhando a candidata com a fanpage que mais apresentou publicações com abordagem feminista, Fátima Bezerra se destacou (3,8\%), e analisando a campanha no Facebook, percebe-se o discurso da mulher forte, trabalhadora, que luta contra as dificuldades. Ao contrário, Jandira Feghali foi a candidata com postagens mais voltadas para uma abordagem feminina $(5,8 \%)$, o que revela uma surpresa, por se tratar de uma mulher na política conhecida pelo seu posicionamento feminista. 
Observa-se nos posts de Feghali o discurso de mãe, além do cuidado enquanto médica.

O que se pode identificar com isso é que todas as mulheres candidatas analisadas nessa pesquisa consideraram pouco o gênero no discurso das postagens no Facebook, e quando o fazem é de forma a reforçar os estereótipos femininos. Olhando especificamente para o Maranhão, Roseana Sarney e Eliziane Gama - junto à Lúcia Vânia $(\mathrm{GO})$ - foram as candidatas que menos apresentaram um discurso feminista, com apenas $0,1 \%$ dos posts. É um dado que chama a atenção, pois as demais candidatas se sobressaíram na abordagem feminista em relação a essas três mulheres. Pensando no contexto sociocultural, o tradicionalismo da sociedade pode ter contribuído para campanhas menos voltadas para o feminismo. Um ponto positivo é que todas as seis candidatas, pelo menos em um post, abordaram de alguma forma o feminismo - seja enaltecendo a luta das mulheres, ou reconhecendo o papel delas etc.

A seguir, a Tabela 4 indica o direcionamento do discurso, ou seja, se as postagens são destinadas às mulheres, a outras minorias (idosos, deficientes, indígenas, negros etc.) ou se não possuem nenhuma referência ao gênero.

Tabela 4 - Direcionamento do discurso por candidata

\begin{tabular}{c|c|c|c|c|c}
\hline \multicolumn{2}{c|}{} & $\begin{array}{c}\text { Destina-se a } \\
\text { outras } \\
\text { mulheres }\end{array}$ & $\begin{array}{c}\text { Destina-se a } \\
\text { outras } \\
\text { minorias }\end{array}$ & $\begin{array}{c}\text { Sem referência } \\
\text { ao gênero }\end{array}$ & Total \\
\hline \multirow{3}{*}{ Ângela Portela } & $\mathrm{N}$ & 11 & 4 & 184 & 199 \\
\cline { 2 - 6 } & $\%$ & $0,6 \%$ & $0,2 \%$ & $9,4 \%$ & $10,2 \%$ \\
\hline \multirow{3}{*}{ Fátima Bezerra } & $\mathrm{N}$ & 10 & 7 & 517 & 534 \\
\cline { 2 - 6 } Roseana Sarney & $\%$ & $0,5 \%$ & $0,4 \%$ & $26,4 \%$ & $27,3 \%$ \\
\hline \multirow{3}{*}{ Eliziane Gama } & $\mathrm{N}$ & 2 & 2 & 105 & 109 \\
\cline { 2 - 6 } & $\%$ & $0,1 \%$ & $0,1 \%$ & $5,4 \%$ & $5,6 \%$ \\
\cline { 2 - 6 } & $\mathrm{N}$ & 3 & 0 & 327 & 330 \\
\hline \multirow{3}{*}{ Lúcia Vânia } & $\mathrm{N}$ & $0,2 \%$ & $0,0 \%$ & $16,7 \%$ & $16,9 \%$ \\
\cline { 2 - 6 } & $\%$ & $0,3 \%$ & $0,3 \%$ & $11,2 \%$ & $11,8 \%$ \\
\hline \multirow{3}{*}{ Jandira Feghali } & $\mathrm{N}$ & 30 & 14 & 510 & 554 \\
\hline \multirow{2}{*}{ Total } & $\mathrm{N}$ & $1,5 \%$ & $0,7 \%$ & $26,0 \%$ & $28,3 \%$ \\
\cline { 2 - 6 } & $\%$ & $3,2 \%$ & $1,7 \%$ & $95,1 \%$ & $100,0 \%$ \\
\hline
\end{tabular}

Fonte: COPS (2019). 
Os dados mostram que, majoritariamente, o discurso das candidatas nos posts das fanpages foi sem referência ao gênero, com 95,1\%. Considera-se esse um percentual elevado, tendo em vista que se trata de campanhas femininas. Ter candidatas mulheres não significa necessariamente que elas vão sempre se dirigir às eleitoras, mas que em tese isso deveria ser um diferencial para que elas pudessem se aproximar do público feminino (que é a maior parte da população brasileira) e conquistar votos. Isso sinaliza que as candidatas não procuraram incorporar ao seu discurso questôes importantes às mulheres, demonstrando que ter mulheres disputando cargos eletivos não garante, num primeiro momento, a preocupação em lutar pelo direito das mulheres.

A candidata que mais publicou conteúdo voltado para as mulheres foi Jandira Feghali (1,5\%). Neste tipo de postagem eram encontradas mensagens apelando para que as mulheres lutassem pelos seus direitos, e também foi ela a que mais destinou posts para outras minorias, embora tenha feito em pouquíssimas postagens $(0,7 \%)$. Fátima Bezerra, que na tabela anterior apresentou o maior percentual de abordagem de um discurso feminista, aqui ficou em terceiro lugar quando se direcionou às mulheres $(0,5 \%)$, ou seja, a candidata postou conteúdo com viés feminista, mas quase sempre em referência a si própria ("eu sou uma mulher trabalhadora”, por exemplo).

Ângela Portela destinou o discurso às mulheres em $0,6 \%$ das publicaçóes da fanpages, e Lúcia Vânia dedicou $0,3 \%$ dos posts às eleitoras, especialmente abordando a Lei Maria da Penha, da qual foi redatora. Eliziane Gama e Roseana direcionaram o discurso para as eleitoras em apenas $0,2 \%$ e $0,1 \%$, respectivamente. Assim, percebe-se que parte das mulheres candidatas quase não falava para as mulheres eleitoras, e menos ainda para idosos, indígenas, negros etc., e o discurso se concentrou na generalização, o que é um ponto negativo quando se leva em conta as poucas propostas de campanha específicas para as mulheres.

A Tabela 5 analisa se houve referência ao movimento feminista no discurso das candidatas nas postagens do Facebook. 
Camilla Quesada Tavares e Nayara Nascimento de Sousa

Tabela 5 - Referência ao movimento feminista por candidata

\begin{tabular}{c|c|c|c|c}
\hline \multicolumn{2}{c|}{} & Náo & Sim & Total \\
\hline \multirow{3}{*}{ Ângela Portela } & $\mathrm{N}$ & 199 & 0 & 199 \\
\cline { 2 - 5 } Fátima Bezerra & $\%$ & $10,2 \%$ & $0,0 \%$ & $10,2 \%$ \\
\hline \multirow{3}{*}{ Roseana Sarney } & $\mathrm{N}$ & 532 & 2 & 534 \\
\cline { 2 - 5 } & $\%$ & $27,2 \%$ & $0,1 \%$ & $27,3 \%$ \\
\cline { 2 - 5 } Eliziane Gama & $\mathrm{N}$ & 109 & 0 & 109 \\
\hline \multirow{3}{*}{ Lúcia Vânia } & $\mathrm{N}$ & $5,6 \%$ & $0,0 \%$ & $5,6 \%$ \\
\hline \multirow{3}{*}{ Jandira Feghali } & $\%$ & $16,9 \%$ & 0 & 330 \\
\cline { 2 - 5 } & $\mathrm{N}$ & 230 & $0,0 \%$ & $16,9 \%$ \\
\hline \multirow{2}{*}{ Total } & $\mathrm{N}$ & $11,7 \%$ & 2 & 232 \\
\hline & $\mathrm{N}$ & $27,4 \%$ & 17 & $11,8 \%$ \\
\hline & $\%$ & 1.937 & $0,9 \%$ & $28,1 \%$ \\
\hline
\end{tabular}

Fonte: COPS (2019).

Embora todas as candidatas abordassem em algum momento um discurso feminista, algumas mais do que outras, conforme a Tabela 3 indicou, somente Feghali, Lúcia Vânia e Fátima Bezerra fizeram referência ao movimento feminista nas publicações, seja com um termo, gesto ou imagem ligada ao feminismo. Ângela Portela, Roseana e Eliziane Gama não publicaram conteúdos com essa característica, o que indica mais uma vez a campanha mais voltada para o tradicionalismo.

Já foi citado que Jandira Feghali é conhecida por seu posicionamento feminista na política, e os dados reforçam isso, com $0,9 \%$ das publicaçóes de sua fanpage fazendo referência ao movimento. Feghali náo foi a candidata que mais apresentou um discurso feminista nas postagens, mas foi a que mais citou o feminismo, e aqui percebemos a importância da análise desses pontos separadamente, tendo em vista que ela oportunizou mais visibilidade para o movimento na sua campanha. Fátima Bezerra e Lúcia Vânia fizeram duas postagens com referência ao feminismo ( $0,1 \%$ para ambas), e a candidata ao Senado pelo estado de Goiás surpreende por não ter abertamente uma relação com o movimento.

$\mathrm{O}$ próximo dado demonstra se as postagens nas fanpages das candidatas fizeram ou não crítica à baixa participação das mulheres na política, para verificar se foi uma questão levantada por elas, até mesmo como estratégia de campanha. 
Tabela 6 - Crítica à baixa participação feminina na política por candidata

\begin{tabular}{c|c|c|c|c}
\hline \multicolumn{2}{c}{} & Não & Sim & Total \\
\hline \multirow{3}{*}{ Ângela Portela } & $\mathrm{N}$ & 198 & 1 & 199 \\
\cline { 2 - 5 } & $\%$ & $10,1 \%$ & $0,1 \%$ & $10,2 \%$ \\
\hline \multirow{3}{*}{ Fátima Bezerra } & $\mathrm{N}$ & 534 & 0 & 534 \\
\cline { 2 - 5 } Roseana Sarney & $\%$ & $27,3 \%$ & $0,0 \%$ & $27,3 \%$ \\
\hline \multirow{3}{*}{ Eliziane Gama } & $\mathrm{N}$ & 109 & 0 & 109 \\
\cline { 2 - 5 } & $\%$ & $5,6 \%$ & $0,0 \%$ & $5,6 \%$ \\
\hline \multirow{3}{*}{ Lúcia Vânia } & $\mathrm{N}$ & 327 & 3 & 330 \\
\hline \multirow{3}{*}{ Jandira Feghali } & $\mathrm{N}$ & $16,7 \%$ & $0,2 \%$ & $16,9 \%$ \\
\cline { 2 - 5 } & $\%$ & $11,8 \%$ & 1 & 232 \\
\cline { 2 - 5 } & $\mathrm{N}$ & 539 & $0,1 \%$ & $11,8 \%$ \\
\hline Total & $\mathrm{N}$ & 1.938 & $0,8 \%$ & $28,3 \%$ \\
\cline { 2 - 5 } & $\%$ & $99,0 \%$ & 20 & 1.958 \\
\hline
\end{tabular}

Fonte: COPS (2019).

Coincidência ou não, os dados mostram que as duas candidatas ao Governo de estados, Fátima Bezerra e Roseana, foram as únicas a não criticar a baixa participação feminina na política na campanha online do Facebook - 0,0\%. Feghali foi a que mais levantou essa questão, em $0,8 \%$ dos posts, o que pode ser explicado pelo seu engajamento feminista na política, e também pelo reconhecimento da pouca representatividade das mulheres na Câmara Federal - apesar de ter feito isso em poucas postagens. Já as candidatas ao Senado, Ângela Portela, Lúcia Vânia e Eliziane Gama, ainda que pouco, criticaram a baixa atuação feminina nas esferas do poder. Chama atenção que Fátima Bezerra, que mais apresentou um discurso voltado para as mulheres nas postagens da fanpage, que destinou considerável número de publicações às mulheres e que fez referência ao feminismo, não tenha citado a pouca representatividade feminina como argumentação e estratégia para conquistar votos.

A penúltima tabela indica quais estereótipos de gênero foram verificados nas publicaçóes do Facebook das candidatas, conforme Panke (2016). 
Camilla Quesada Tavares e Nayara Nascimento de Sousa

Tabela 7 - Estereótipo de gênero por candidata

\begin{tabular}{|c|c|c|c|c|c|c|c|c|c|}
\hline & & $\begin{array}{c}\text { Dona } \\
\text { de } \\
\text { casa }\end{array}$ & Guerreira & Máe & $\begin{array}{c}\text { Atenciosa/ } \\
\text { Sensível }\end{array}$ & Submissa & Trabalhadora & $\begin{array}{c}\text { Náo } \\
\text { identificada }\end{array}$ & Total \\
\hline \multirow{2}{*}{$\begin{array}{l}\text { Ângela } \\
\text { Portela }\end{array}$} & $\mathrm{N}$ & 0 & 4 & 4 & 1 & 5 & 67 & 118 & 199 \\
\hline & $\%$ & $0,0 \%$ & $0,2 \%$ & $0,2 \%$ & $0,1 \%$ & $0,3 \%$ & $3,4 \%$ & $6,0 \%$ & $10,2 \%$ \\
\hline \multirow[b]{2}{*}{$\begin{array}{l}\text { Fátima } \\
\text { Bezerra }\end{array}$} & $\mathrm{N}$ & 0 & 66 & 31 & 42 & 0 & 70 & 325 & 534 \\
\hline & $\%$ & $0,0 \%$ & $3,4 \%$ & $1,6 \%$ & $2,1 \%$ & $0,0 \%$ & $3,6 \%$ & $16,6 \%$ & $27,3 \%$ \\
\hline \multirow[b]{2}{*}{$\begin{array}{c}\text { Roseana } \\
\text { Sarney }\end{array}$} & $\mathrm{N}$ & 0 & 10 & 1 & 7 & 0 & 22 & 69 & 109 \\
\hline & $\%$ & $0,0 \%$ & $0,5 \%$ & $0,1 \%$ & $0,4 \%$ & $0,0 \%$ & $1,1 \%$ & $3,5 \%$ & $5,6 \%$ \\
\hline \multirow[b]{2}{*}{$\begin{array}{l}\text { Eliziane } \\
\text { Gama }\end{array}$} & $\mathrm{N}$ & 0 & 1 & 1 & 1 & 0 & 0 & 327 & 330 \\
\hline & $\%$ & $0,0 \%$ & $0,1 \%$ & $0,1 \%$ & $0,1 \%$ & $0,0 \%$ & $0,0 \%$ & $16,7 \%$ & $16,9 \%$ \\
\hline \multirow[b]{2}{*}{$\begin{array}{l}\text { Lúcia } \\
\text { Vânia }\end{array}$} & $\mathrm{N}$ & 1 & 96 & 4 & 19 & 2 & 85 & 25 & 232 \\
\hline & $\%$ & $0,1 \%$ & $4,9 \%$ & $0,2 \%$ & $1,0 \%$ & $0,1 \%$ & $4,3 \%$ & $1,3 \%$ & $11,8 \%$ \\
\hline \multirow[b]{2}{*}{$\begin{array}{l}\text { Jandira } \\
\text { Feghali }\end{array}$} & $\mathrm{N}$ & 2 & 265 & 15 & 33 & 1 & 19 & 219 & 554 \\
\hline & $\%$ & $0,1 \%$ & $13,5 \%$ & $0,8 \%$ & $1,7 \%$ & $0,1 \%$ & $1,0 \%$ & $11,2 \%$ & $28,3 \%$ \\
\hline \multirow[b]{2}{*}{ Total } & $\mathrm{N}$ & 3 & 442 & 56 & 103 & 8 & 263 & 1.083 & 1.958 \\
\hline & $\%$ & $0,2 \%$ & $22,6 \%$ & $2,9 \%$ & $5,3 \%$ & $0,4 \%$ & $13,4 \%$ & $55,3 \%$ & $100,0 \%$ \\
\hline
\end{tabular}

Fonte: COPS (2019).

A variável "não identificada" se refere aos posts em que não se observam estereótipos, com 55,3\%. Analisando os estereótipos que mais se sobressaíram para cada candidata, nota-se distinçóes entre algumas: Jandira Feghali $(13,5 \%)$ e Lúcia Vânia $(4,9 \%)$ usaram como estratégia a imagem de guerreiras, que vencem as barreiras impostas na sociedade, se posicionam na luta das mulheres e buscam seu espaço na política. Ângela Portela $(3,4 \%)$, Roseana $(1,1 \%)$ e Fátima Bezerra $(3,6 \%)$ apresentaram a característica de trabalhadoras a serviço dos cidadãos e cidadãs, que já implementaram ações e querem fazer mais, que apresentam soluçóes e estão dispostas a lutar por melhorias. Já Eliziane Gama foi a que menos utilizou algum tipo de estereótipo - apenas $0,1 \%$, como guerreira, mãe e atenciosa/sensível -, talvez na tentativa de construir uma campanha mais neutra.

Importante observar que todas as mulheres se apresentaram como mães, e nas fanpages era recorrente encontrar falas do tipo "eu sou mãe, sou candidata e quero te representar", configurando uma estratégia para se aproximar das eleitoras, especialmente nas publicações de Fátima Bezerra (1,6\%) e Jandira Feghali $(0,8 \%)$, ambas eleitas. Outra característica que esteve presente em todas as candidaturas no Facebook foi a de atenciosa/sensível, e um dos argumentos que se verifica é: "é 
preciso ter sensibilidade para governar e entender os problemas do povo", também como forma de criar uma relaçáo de proximidade com o eleitorado, principalmente nas postagens de Bezerra (2,1\%) e Feghali (1,7\%), mais uma vez.

Os estereótipos de dona de casa e submissa foram os menos recorrentes nos posts das candidatas, se distanciando das imagens da mulher do lar e que depende do marido ou de outra figura masculina. Assim, destaca-se que as candidatas, com exceção de Eliziane Gama, tiveram como estratégia mostrar que são fortes, líderes, que trabalham, possuem méritos profissionais e são capacitadas para os cargos a que concorriam e, de forma complementar, indicaram que possuem sensibilidade e que são mães, equilibrando os estereótipos.

Por fim, o último dado indica se as candidatas utilizaram a estratégia do patrono nas postagens das fanpages do Facebook, para identificar se elas recorreram à influência de outros políticos na conquista dos votos. Tavares (2013) explica que se considera como patrono o político que possui prestígio social e é conhecido dos eleitores/as, de forma que apoia publicamente um candidato e/ou candidata com quem tem relação pessoal ou política. A função do patrono é ajudar sua candidata ou candidato na campanha e, assim, angariar votos.

Tabela 8 - Patrono das candidatas

\begin{tabular}{|c|c|c|c|c|}
\hline & & Náo & Sim & Total \\
\hline \multirow[b]{2}{*}{ Ângela Portela } & $\mathrm{N}$ & 195 & 4 & 199 \\
\hline & $\%$ & $10,0 \%$ & $0,2 \%$ & $10,2 \%$ \\
\hline \multirow[b]{2}{*}{ Fátima Bezerra } & $\mathrm{N}$ & 379 & 155 & 534 \\
\hline & $\%$ & $19,4 \%$ & $7,9 \%$ & $27,3 \%$ \\
\hline \multirow[b]{2}{*}{ Roseana Sarney } & $\mathrm{N}$ & 105 & 4 & 109 \\
\hline & $\%$ & $5,4 \%$ & $0,2 \%$ & $5,6 \%$ \\
\hline \multirow[b]{2}{*}{ Eliziane Gama } & $\mathrm{N}$ & 123 & 207 & 330 \\
\hline & $\%$ & $6,3 \%$ & $10,6 \%$ & $16,9 \%$ \\
\hline \multirow[b]{2}{*}{ Lúcia Vânia } & $\mathrm{N}$ & 215 & 17 & 232 \\
\hline & $\%$ & $11,0 \%$ & $0,9 \%$ & $11,8 \%$ \\
\hline \multirow[b]{2}{*}{ Jandira Feghali } & $\mathrm{N}$ & 309 & 245 & 554 \\
\hline & $\%$ & $15,8 \%$ & $12,5 \%$ & $28,3 \%$ \\
\hline \multirow[b]{2}{*}{ Total } & $\mathrm{N}$ & 1.326 & 632 & 1.958 \\
\hline & $\%$ & $67,7 \%$ & $32,3 \%$ & $100,0 \%$ \\
\hline
\end{tabular}

Fonte: COPS (2019)

Em 32,3\% das publicações, verifica-se a aparição ou citação de patronos, o que representa percentual relativamente alto. É interessante observar que o expresidente Lula teve papel importante na campanha de Fátima Bezerra (PT) e Jandira 
Feghali (PCdoB), aparecendo em 7,9\% e 12,5\% dos posts das candidatas, respectivamente. Ambas ressaltavam as realizaçóes do ex-presidente, e isso representava um parâmetro para as propostas e promessas das candidatas. Já Eliziane Gama (PPS) apoiava-se em Flávio Dino, reeleito governador do Maranhão em 2018, para alavancar sua campanha - ele aparece em $10,6 \%$ das postagens da candidata.

Com um histórico de escândalos na política, o patrono de Roseana, José Sarney, esteve presente em apenas $0,2 \%$ das publicaçóes na fanpage da candidata, que optou como estratégia apresentar-se sem o sobrenome, para tentar se desvencilhar da imagem do pai durante a campanha. Assim como Roseana, Ângela Portela foi a que menos recorreu ao patrono na campanha online do Facebook $(0,2 \%)$.

Chama a atenção que a três candidatas que mais utilizaram o patrono foram eleitas (Fátima Bezerra, Eliziane Gama e Jandira Feghali), e as três que disputavam com o menor apoio dos patronos náo venceram para os cargos que concorriam (Roseana Sarney, Ângela Portela e Lúcia Vânia). Não é possível afirmar que o patrono foi decisivo no êxito das candidatas, mas pode ser um indício de influência para o voto dos eleitores e eleitoras. Os principais achados desta pesquisa são abordados a seguir.

\section{Considerações finais}

O estudo partiu da campanha nas redes sociais digitais de mulheres candidatas nas eleiçôes de 2018 para analisar como as questôes de gênero aparecem no discurso delas nas fanpages do Facebook. Foram coletadas e codificadas 1.958 postagens durante a campanha eleitoral das candidatas: Ângela Portela (PDT-RR), Jandira Feghali (PCdoB-RJ), Lúcia Vânia (PSB-GO), Eliziane Gama (PPS-MA), Roseana Sarney (MDB-MA) e Fátima Bezerra (PT-RN). Assim, foi possível notar que as candidatas pouco apresentam um discurso permeado por questôes de gênero e, quando o fizeram, majoritariamente adotaram a abordagem feminina, reforçando os estereótipos. Apesar disso, Fátima Bezerra se destacou com o discurso mais voltado ao viés feminista dentre as candidatas.

Relevante mencionar que Fátima Bezerra e Jandira Feghali, ambas eleitas, adotaram estratégias de forma a equilibrar a imagem da mulher guerreira e trabalhadora, apelando para a luta feminina e a capacidade de realizar melhorias, e que também é mãe e sensível. Já as demais focaram mais em um tipo de estereótipos - Lúcia Vânia como guerreira, e Ângela Portela e Roseana como trabalhadoras. Eliziane permaneceu neutra, sem muitos discursos estereotipados. 
Também se faz interessante pontuar que o patrono esteve mais presente na campanha das candidatas eleitas (Eliziane Gama, Fátima, Bezerra e Jandira Feghali), e isso pode ser indício da influência dessa figura na conquista do voto dessas mulheres. Esses achados revelam que as campanhas das candidatas ainda estão baseadas no imaginário comum que se tem do papel da mulher na sociedade. Ao mesmo tempo que procuram recorrer a estereótipos relacionados à esfera pública da vida social como o de pessoa trabalhadora -, o discurso de mãe e de mulher sensível ainda se faz presente, características ligadas ao universo feminino. Por outro lado, foi possível constatar o discurso marcado por estereótipos náo predominou nas postagens dessas candidatas no Facebook. Embora não seja possível fazer generalizações, esse dado oferece evidências a serem investigadas mais a fundo, e de modo comparativo, por trabalhos posteriores.

Sobre os temas dos posts das fanpages, a maior parte se dedicou à metacampanha, corroborando com as constatações de estudos sobre campanha no Facebook. Mesmo em se tratando de campanhas de mulheres, essa rede social não foi utilizada para fazer uma campanha mais pragmática, tampouco discutir sobre temas que interessem diretamente a essa parcela da população, como a luta por direitos. As candidatas analisadas neste trabalho seguiram uma linha mais tradicional, não fugindo muito das características das campanhas masculinas. Ainda em consonância com pesquisas da área, a educação também se destacou, e autores/as apontam que temas relacionados ao assistencialismo e cuidado tendem a estar mais presentes em campanhas femininas. Um achado interessante e que difere de trabalhos anteriores foi que a temática segurança foi a segunda mais abordada pelas candidatas, o que pode ser explicado pelas crises nesse setor nos estados do Rio Grande do Norte e Rio de Janeiro. Apesar de ser considerado um tema "masculino", as candidatas procuraram abordá-lo na campanha online.

Assim, este trabalho oferece novas constatações sobre as candidaturas femininas, focadas sobretudo nas redes sociais - um nicho ainda pouco explorado nos estudos brasileiros. Ainda que não se trate de uma amostra representativa, o que representa um dos limites da presente pesquisa, os resultados fornecem evidências que podem ser observadas em outros contextos e testadas em trabalhos futuros. Por fim, não basta apenas ter mulheres disputando cargos públicos, é necessário investigar suas propostas e estratégias a fim de verificar se elas vão de encontro às necessidades das eleitoras. Só com propostas voltadas às mulheres é possível garantir uma representação de fato, para que seus direitos sejam preservados e ampliados. 
- Camilla Quesada Tavares é Doutora em Comunicação pela Universidade Federal Fluminense. Professora adjunta da graduação e do Programa de Pós-Graduação em Comunicação da Universidade Federal do Maranhão. Líder do grupo de pesquisa em Comunicação, Política e Sociedade (COPS/UFMA). E-mail: camilla.tavares8@gmail.com.

- Nayara Nascimento de Sousa é Graduada em Pedagogia pela Universidade Estadual do Maranhão. Graduanda de Comunicação Social (Jornalismo) da Universidade Federal do Maranhão. Pesquisadora do grupo de pesquisa em Comunicação, Política e Sociedade (COPS). E-mail: nayara.nns@hotmail.com.

\section{Referências}

AGGIO, Camilo; REIS, Lucas. Campanha eleitoral no Facebook: usos, configuraçóes e o papel atribuído a esse site por três candidatos eleitos nas eleições municipais de 2012. Revista Compolítica, v. 2, n 3, p. 155-188, jul./dez. 2013.

ALBUQUERQUE, Afonso de. Aqui você vê a verdade na tevê: a propaganda política na televisão. Rio de Janeiro: MCII/UFF, 1999.

ALBUQUERQUE, Afonso de; TAVARES, Camilla Quesada. Horário Gratuito de Propaganda Eleitoral: estilo, estratégias, alcance e os desafios para o futuro. In: FIGUEIREDO, Argelina Cheibub; BORBA, Felipe (Orgs.). 25 anos de eleiçôes presidenciais no Brasil. Curitiba: Appris, 2018. p. 147-169.

ALBUQUERQUE, Ana Luiza. Com polícia em greve, RN decreta calamidade na segurança pública. Folha de S. Paulo, 6 jan. 2018. Disponível em: <https://www1.folha.uol.com.br/cotidiano/2018/01/1948509-com-policia-em-greve-rn-decretacalamidade-na-seguranca-publica.shtml>. Acesso em: 11 nov. 2019.

ARAÚJO, Clara. Partidos políticos e gênero: mediaçóes nas rotas de ingresso das mulheres na representação política. Revista Sociologia e Política, n. 24, p. 193-215, 2005. 
ARAÚJO, Clara; ALVES, José Eustáquio Diniz. Impactos de indicadores sociais e do sistema eleitoral sobre as chances das mulheres nas eleiçôes e suas interaçôes com as cotas. Dados - Revista de Ciências Sociais, v. 50, n. 3, p. 535-577, 2007.

BARBON, Júlia; VETTORAZZO, Lucas. Intervenção federal no RJ faz 6 meses; entenda o que aconteceu até agora. Folha de S. Paulo, 15 ago. 2018. Disponível em: <https://www1.folha.uol.com.br/cotidiano/2018/08/intervencao-federal-no-rj-faz-6-meses-entendao-que-aconteceu-ate-agora.shtml>. Acesso em: 11 nov. 2019.

BARBOSA, Anderson; RAFAEL, Norton. Maior presídio do RN tem práticas de tortura, diz relatório. G1, 28 nov. 2018. Disponível em: <https://g1.globo.com/rn/rio-grande-donorte/noticia/2018/11/28/presidio-potiguar-tem-serissimas-semelhancas-com-praticas-de-torturarealizadas-em-abu-ghraib-diz-relatorio.ghtml>. Acesso em: 11 nov. 2019.

BAUER, Martin W. Análise de conteúdo clássica: uma revisão. In: BAUER, Martin W.; GASKELL, George. Pesquisa qualitativa com texto, imagem e som: um manual prático I. Tradução de Pedrinho A. Guareschi. 2. ed. Petrópolis: Vozes, 2002.p. 189-217.

BEARD, Mary. Mulheres e poder: um manifesto. São Paulo: Planeta do Brasil, 2018.

BEZERRA, Fátima. [Homepage]. Disponível em: <https://www.facebook.com/FatimaBezerra13/>. Acesso em: 4 set. 2019.

BRASIL. Pesquisa Brasileira de Mídia. Governo Federal: Secretaria de Comunicação Social, 2016.

CAMPOS, Ligia Fabris. Litígio estratégico para igualdade de gênero: o caso das verbas de campanha para mulheres candidatas. Revista Direito e Praxis, v. 10, n. 1, p. 593-629, 2019.

CERVI, Emerson Urizzi. O uso do HGPE como recurso partidário em eleiçóes proporcionais no Brasil: um instrumento de análise de conteúdo. Opinião Pública, v. 17, n. 1, p. 106-136, jun. 2011.

COMITÊ GESTOR DA INTERNET NO BRASIL (COMITÊ). TIC Domicílios 2018. 2019. Disponível em: < https://www.cetic.br/pesquisa/domicilios/>. Acesso em: 27 ago. 2019.

FEGHALI, Jandira. [Homepage]. Disponível em: <https://www.facebook.com/sigajandira2/>. Acesso em: 10 nov. 2019.

FINAMORE, Claudia Maria; CARVALHO, João Eduardo Coin de. Mulheres candidatas: relações entre gênero, mídia e discurso. Estudos em Jornalismo e Mídia, v. 14, n. 2, p. 347-362, 2006.

GAMA, Eliziane. [Homepage]. Disponível em: <https://www.facebook.com/elizianegama/>. Acesso em: 4 set. 2019.

HOLTZ-BACHA, Christina. Quem cuida das crianças? A representação das mulheres do alto escalão político pelos media. Compolítica, v. 2, n. 3, p. 45-60, jul./dez. 2013.

KRIPPENDORFF, Klaus. Content Analysis. In: BARNOUW, Erik et al. International encyclopedia of communication. New York: Oxford University Press, 1989.

MARTINS, Joyce Miranda Leão; ALTMANN, Cristina. Os usos do gênero na campanha presidencial de 2014: mulheres na propaganda eleitoral brasileira. Revista Teoria \& Pesquisa, v. 27, n. 1, p. 48$70,2018$.

MASSAMBANI, Ana Claudia; CERVI, Emerson Urizzi. A participação das mulheres no HGPE proporcional: uma análise comparativa das campanhas para deputado federal no Paraná em 2006 e 2010. In: XII CONGRESSO DE CIÊNCIAS DA COMUNICAÇÃO NA REGIÃO SUL. Londrina, 2011. 
MASSUCHIN, Michele Goulart; TAVARES, Camilla Quesada. Campanha eleitoral nas redes sociais: estratégias empregadas pelos candidatos à Presidência em 2014 no Facebook. Revista Compolítica, v. 2, n. 5, p. 75-112, 2015.

MENDONÇA, Ricardo; OGANDO, Ana Carolina. Discursos sobre o feminino: um mapeamento dos programas eleitorais de Dilma Rousseff. Revista Brasileira de Ciências Sociais, v. 28, n. 83, p. 195-243, out. 2013.

MIGUEL, Luis Felipe; BIROLI, Flavia. Feminismo e política. São Paulo: Boitempo, 2014.

MIGUEL, Luis Felipe; BIROLI, Flavia. Práticas de gênero e carreiras políticas: vertentes explicativas. Estudos Feministas, v. 3, n. 18, p. 653-679, set./dez. 2010.

MULHERES representam 52\% do eleitorado brasileiro. Tribunal Superior Eleitoral, 06 mar. 2018. Disponível em: <http://www.tse.jus.br/imprensa/noticias-tse/2018/Marco/mulheres-representam52-do-eleitorado-brasileiro>. Acesso em: 10 ago. 2019.

NÚMERO de mulheres eleitas em 2018 cresce 52,6\% em relação a 2014. Tribunal Superior Eleitoral, 08 mar. 2019. Disponível em: <http://www.tse.jus.br/imprensa/noticias-tse/2019/Marco/numerode-mulheres-eleitas-em-2018-cresce-52-6-em-relacao-a-2014>. Acesso em: 10 ago. 2019.

OLIVEIRA, Filipe. Facebook chega a 127 milhões de usuários mensais no Brasil. Folha de S. Paulo, 18 jul. 2018. Disponível em: <https://www1.folha.uol.com.br/tec/2018/07/facebook-chega-a-127milhoes-de-usuarios-mensais-no-brasil.shtml>. Acesso em: 10 ago. 2019.

PANKE, Luciana. Campanhas eleitorais para mulheres: desafios e tendências. Curitiba: UFPR, 2016.

PANKE, Luciana; IASULAITIS, Sylvia. Mulheres no poder: aspectos sobre o discurso feminino nas campanhas eleitorais. Opinião Pública, v. 22, n. 2, p. 385-417, ago. 2016.

PANKE, Luciana; THAUNY, Jeferson. Características do discurso eleitoral no Facebook. In: CASTILHO, Alessandra de; ROCHA, Daniela; MACEDO, Roberto Gondo (Orgs.). Comunicação política na esfera pública: democracia, eleições e cidadania no Brasil. Capivari: Nova Consciência, 2013. p. 165-181.

PENTEADO, Claudio Luis de Camargo. Facebook e campanha eleitoral digital. Em Debate, v. 4, n. 4, p. 41-53, jul. 2012.

PORTELA, Ângela. [Homepage]. Disponível em: <https://www.facebook.com/angelaportelaRR/>. Acesso em: 4 set. 2019.

REZENDE, Daniela Leandro. Desafios à representação política de mulheres na Câmara dos Deputados. Revista Estudos Feministas, v. 3, n. 25, p. 1199-1218, set./dez. 2017.

SACCHET, Teresa; SPECK, Bruno Wilhelm. Financiamento eleitoral, representação política e gênero: uma análise das eleiçôes de 2006. Opinião Pública, v. 18, n. 1, p. 177-197, 2012.

SILVA, Maria Paula Almada e; ROSSETTO, Graça Nascimento Penha; CARREIRO, Rodrigo. Diferentes objetivos, diferentes apropriaçóes? O uso do Facebook por iniciativas civis de democracia digital no Brasil. Verso e Reverso, v. 28, n. 68, p. 142-151, maio/ago. 2014.

TAVARES, Camilla Quesada. "Para presidente, vote na gente”: as personalidades presentes nos programas do PT e PSDB veiculados no horário eleitoral de 2002, 2006 e 2010. 119 f. 2013. Dissertação (Mestrado em Ciências Sociais Aplicadas) - Programa de Pós-Graduação em Ciências Sociais, Universidade Estadual de Ponta Grossa, Ponta Grossa, 2013.

TAVARES, Camilla Quesada; MASSUCHIN, Michele Goulart. Mulheres na política: a presença das candidatas a deputada federal do Paraná na propaganda eleitoral televisiva de 2014. Animus, v. 18, n. 37, p. 62-83, 2019. 
VÂNIA, Lúcia. [Homepage]. Disponível em: <https://www.facebook.com/luciavaniasenadora/>. Acesso em: 4 set. 2019.

Texto recebido em 05 de setembro de 2019. Aprovado em 21 de novembro de 2019. 